\section{EASILY COMMUNICATE THE BENEFITS OF SUGARFREE GUM}

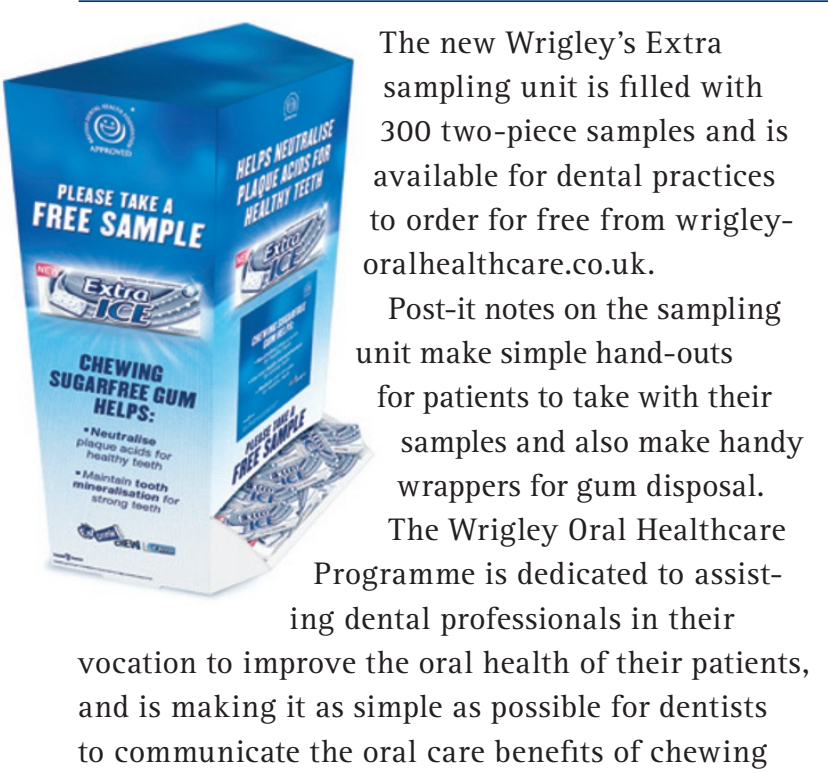

sugarfree gum to patients with the new sampling unit.

Chewing sugarfree gum after eating and drinking is clinically proven to maintain healthy $\mathrm{pH}$ levels and defend against plaque acid attacks.

To order samples of Extra for your practice via the Wrigley Oral Healthcare Programme visit the dedicated site for dental professionals in the UK: www. wrigleyoralhealthcare.co.uk.

Please note that the image shows 10-piece pack samples, when in reality the units contain two-piece samples.

\title{
BRAND NEW WEBSITE FOR PRESTIGIOUS TRAINING COMPANY
}

Manchester company Tipton Training is launching a new website designed to give prospective delegates access to the information and skills they need to provide the quality dental services needed for private practices.

Tipton Training has been providing dental professionals across the UK with the very best educational training for almost 25 years. The new website will inform dental professionals of the additional learning they can undertake within the fields of restorative, implant and cosmetic and aesthetic dentistry.

Each course offers delegates practical training combined with theoretical lectures and seminars, under the direct supervision of experienced lectures and some of the UK's leading practitioners. The academy's new website will feature a programme of web-based learning for dental professionals looking for a more flexible way of getting the knowledge they need to succeed.

Tipton Training can also share expert advice with dentists on how to structure their practices to attract new patients and improve profitability.

For further information about Tipton Training and their dental training courses, visit www. tiptontraining.co.uk or call 01613487848.

\section{STUDENTS DESIGN STRIKING NEW PRODUCT}

Two dental students from Queen's University Belfast have designed a brand new oral health product:

Flipper Hygienic Toothbrush Holders, distributed exclusively by CW Distributions.

Flipper anti-bacterial toothbrush holders offer a cleaner, more hygienic and fun way to store toothbrushes. The children's ranges are intended to motivate children into looking after their oral health. The 'Animo Jr' range features 12 animal designs including a giraffe, tiger, pig, panda and cow; in 'ToothFairy' there are 12 colourful toothshaped designs. There is also an adult version of the product, 'Basic', with a sleek and simple design.

Fourth year students William Maguire and Callum McCandless developed the Hygienic Toothbrush

\section{A COMPLETE DECONTAMI-} NATION SYSTEM

schülke's Dental Water Line Solution is a complete decontamination system for dental unit water lines.

Bacteria in DUWLs can lead to biofilm build up, providing a haven for dangerous microorganisms. Thirty percent of practice staff have shown exposure to Legionella in studies as a result of water line infection.

Dental Water Line Solution from schülke is clinically proven to remove $100 \%$ of biofilm in one easy procedure, and with proper use can effectively prevent bacteria from returning with continuous treatment.

The schülke Dental Waterline Solution has no adverse effects on equipment, patients or the environment, and can even be safely consumed in its neat form. The starter kit includes everything you need to clear your dental unit of colonising bacteria, a set of dip slides for testing output water, as well as a complimentary pack of schülke's mikrozid sensitive surface cleansing wipes and a bottle of desderman pure hand gel.

For more information, call 0114254 3500. Alternatively, visit www.schulke.com.

ucts should help them pay off their student loans.

Many dental practices already stock the Hygienic Toothbrush Holders, as well as MediCare the largest chemist retail chain in Northern Ireland - and a number of smaller chains.

To find out more visit www. myflipperuk.com.
Holders after completing work They even plan to branch out into a teenage range and to produce an anti-bacterial razor holder.

The young entrepreneurs hope to give something back to their community through raising awareness of good oral health and at the same time the prod-

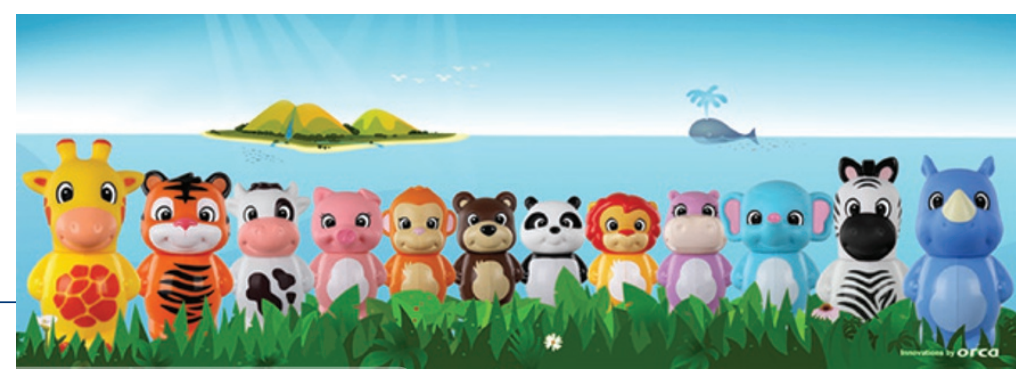

